Check for updates

Cite this: RSC Adv., 2019, 9, 4932

Received 4th January 2019

Accepted 30th January 2019

DOI: $10.1039 / c 9 r a 00082 h$

rsc.li/rsc-advances

\section{Effects of solvents on the DACBO-catalyzed vinylogous Henry reaction of isatin with 3,5- dimethyl-4-nitroisoxazole "on-water" and in solution from QM/MM MC simulations $\uparrow$}

\begin{abstract}
Lian Yang, ${ }^{a}$ Jianming Zhao, ${ }^{a}$ Xin Yang, ${ }^{b}$ Ming Chen ${ }^{a}$ and Ying Xue (DD *a
The mechanism of the DABCO-catalyzed vinylogous Henry reaction of isatin with 3,5-dimethyl-4nitroisoxazole and solvent effects on it have been investigated using density functional theory (DFT) methods and QM/MM Monte Carlo (MC) simulation under "on-water" conditions as well as in methanol and THF solutions. The DFT calculations concluded that Path A, in which DABCO directly catalyzes the reaction of isatin 1a with 3,5-dimethyl-4-nitroisoxazole 2 in water, is the most favorable and the first step, the proton transfer process, is the rate-determining step for the reaction. For the roles of solvents in the reaction, QM/MM MC simulations using free energy perturbation theory and PDDG/PM3 as the QM method have been utilized to predict the free energy profiles. The results indicated that the QM/MM method reproduced well the large rate increases on-water. Solute-solvent energy pair distribution and radial distribution functions were also analyzed and illustrated that hydrogen bonding plays a significant role in stabilizing the transition structures. This work reveals the feasible reaction mechanisms and provides new insight into solvent effects for the DACBO-catalyzed vinylogous Henry reaction.
\end{abstract}

\section{Introduction}

Water, as a green solvent, is nonflammable, nontoxic, and abundant. It is cheaper and milder than most organic solvents. ${ }^{1-8}$ In the past two decades, great progress has been made in the study of organic synthesis in water or watercontaining organic solvents as the reaction medium, ${ }^{\mathbf{9}, 10}$ because water has many unique properties compared to organic solvents, for example, hydrogen bonding, and hydrophilic and hydrophobic interactions with the reactants. The rate enhancing of Diels-Alder reactions in pure water was first exposed by Breslow et al. in the early 1980s. ${ }^{11}$ They found that the reaction rate in water was more than 700 -fold faster than in isooctane, with higher internal (endo) selectivity. This work set a precedent for modern aqueous phase organic reactions. In

${ }^{a}$ College of Chemistry, Key Lab of Green Chemistry and Technology in Ministry of Education, Sichuan University, Chengdu 610064, People's Republic of China. E-mail: yxue@scu.edu.cn; Tel: +862885418330

${ }^{b}$ State Key Laboratory of Biotherapy and Cancer Center, West China Hospital, Sichuan University, Collaborative Innovation Center of Biotherapy, Chengdu 610041, People's Republic of China

$\dagger$ Electronic supplementary information (ESI) available: Illustrations of the transition structures of the proton migration process in solvents methanol and tetrahydrofuran; DFT-calculated free energy profiles of three pathways for the vinylogous Henry reaction in water; the geometry structures of stationary states for the rate-limiting step by employing microsolvent models with one-, threeand six-water clusters; additional radial distribution functions; coordinates of all structures optimized using DFT methods. See DOI: 10.1039/c9ra00082h
2005, Sharpless and co-workers reported some reactions "in water", which means that the reactants are dissolved homogeneously in water with large rate and yield increases compared to organic solvents. ${ }^{12}$ Subsequently, they introduced the concept "on-water", which was defined as a reaction environment where the reaction occurs in an aqueous organic emulsion prepared by vigorously stirring insoluble reactants with water. ${ }^{13,14}$ Since then, water as a reaction medium has received more attention for the synthesis of simple and complex molecules. ${ }^{15-19}$

In 1895, Henry proposed nitroaldol (Henry) reactions between nitroalkanes and carbonyl compounds, which became an important and classic synthetic method for $\mathrm{C}-\mathrm{C}$ bond formation in organic chemistry. ${ }^{20}$ Nevertheless, the reactions encountered low selectivity and side products. Recently, many organocatalytic or metallic-catalyzed Henry reactions have been successfully carried out with enhancement of reactivities and selectivities. ${ }^{21-23}$ However, few vinylogous-type Henry reactions in the aqueous phase had been studied. ${ }^{24-26}$ Nitrogencontaining heterocyclic products are typical natural complex and biologically active molecules. ${ }^{27,28}$ It is essential to find a facile synthetic approach for direct vinylogous Henry reactions with high yield and selectivity in pharmacochemistry and green chemistry. Therefore, effective methods for direct vinylogous Henry reactions have been discovered and explored in recent years. ${ }^{29,30}$

In 2015, Zhang et al. first reported the vinylogous Henry reaction between isatin and 3,5-dialkyl-4-nitroisoxazole, leading 
to isoxazole-substituted 3-hydroxy-2-oxindole derivatives, medicinally important compounds, using water as the solvent for optimizing the reaction conditions at room temperature. ${ }^{29}$ They found that organic base catalysts are more effective than inorganic bases and 1,4-diazabicyclo[2.2.2] octane (DABCO) is the optimal catalyst with a near quantitative yield (>99\%) in 1.5 hours for the synthesis of the desired vinylogous product. Furthermore, the effects of different solvents on the rate and yield of the reaction were observed. In typical cases, when the organic solvent THF was used, a moderate product yield of 53\% was obtained in 12 hours. Using a protic organic solvent such as $\mathrm{CH}_{3} \mathrm{OH}$, the reaction efficiency showed a significant improvement so that the yield was about $92 \%$ after 6 hours. It was also found that water was the most suitable solvent with high yield $(>99 \%)$ and the shortest reaction time (1.5 hours) compared to other organic solvents under "on-water" conditions. ${ }^{29}$ However, the active catalysis mechanism and the internal causes of the remarkable rate enhancement for the reaction in water are still unclear. These require a detailed understanding at the molecular level.

To gain further insights into the effects of the solvents on the rate and geometries of transition states at the theoretical level, in this work, isatin 1a and 3,5-dimethyl-4-nitroisoxazole 2 are selected as the reactants and DABCO as the catalyst to investigate this vinylogous Henry reaction "on-water" and in the organic solvents THF and $\mathrm{CH}_{3} \mathrm{OH}$ (Scheme 1) by using a combination of multiscale computational levels. The computational results will be contrasted with the experimental study by Zhang et al. ${ }^{29}$ First, we adopt density functional theory (DFT) M06-2X/SMD/6-311+G(d,p)//B3LYP/SMD/6-31+G(d,p) methods to investigate the reaction mechanism and obtain the structures of the transition states and ground states in water. Three possible reaction pathways are considered. Then, the effects of three solvents, water, $\mathrm{CH}_{3} \mathrm{OH}$, and THF, on the ratelimiting step of the reaction are studied and compared. Meanwhile, microsolvent models with one, three, and six water molecules are employed for the reaction in water. Finally, to describe the solvent effect correctly, quantum mechanics and molecular mechanics (QM/MM) calculation in conjunction with Monte Carlo (MC) simulation and free energy perturbation (FEP) theory at $298.15 \mathrm{~K}$ and $101.325 \mathrm{kPa}$ are performed for the rate-determining step of the vinylogous Henry reaction "onwater" and in $\mathrm{CH}_{3} \mathrm{OH}$ and THF. The reaction system has been treated using the semiempirical PDDG/PM3 method with complete sampling of the geometry of the reacting systems and explicit representation of the solvent components. The QM/ $\mathrm{MM} / \mathrm{MC}$ method has reproduced very well the experimentally

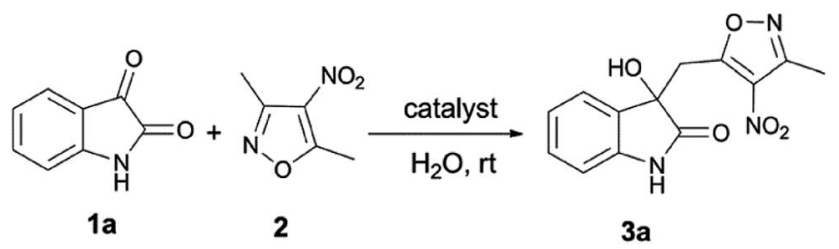

Scheme 1 The vinylogous Henry reaction of isatin 1 a and 3,5dimethyl-4-nitroisoxazole 2 "on-water". observed solvent effects in various reactions, such as $\mathrm{S}_{\mathrm{N}} 2$ reactions, ${ }^{31}$ nucleophilic aromatic substitution reactions, ${ }^{32}$ Cope eliminations, ${ }^{33}$ decomposition of amino acids, ${ }^{34}$ 1,3-dipolar cycloadditions, ${ }^{35,36}$ and aldol reactions. ${ }^{37,38}$ This method can calculate the absolute free energy of activation, $\Delta G^{\neq}$, and characterize the nature of the Henry reaction at atomic-level structural details. The energy pair distribution functions and radial distribution functions (rdfs) are evaluated to further explain the effects of solvent molecules on the reaction.

\section{Computational methods}

The mixed quantum mechanics and molecular mechanics (QM/ MM) calculations were performed using the BOSS 4.9 program $^{39}$ for the reacting systems. The QM method is the semi-empirical PDDG/PM3. ${ }^{40,41}$ Calculations of the energy and atomic charges in the QM method were carried out for every attempted solute move, occurring every 100 configurations in QM/MM simulations. The free energy changes were computed using FEP theory in conjunction with double-wide sampling in Metropolis MC simulations at $25{ }^{\circ} \mathrm{C}$ and $1 \mathrm{~atm}$. To consider the electrostatic contributions to the solute-solvent interaction energy, CM3 charges $^{42}$ were obtained for the solute using PDDG/PM3 calculations with a scaling factor of 1.14. All QM/MM calculations were completed from the stored solvent boxes of the BOSS program. The solvent molecules were represented with the united-atom OPLS ${ }^{\mathbf{4 3 , 4 4}}$ force field for the organic solvents and with the TIP4P model for water. ${ }^{45}$ The systems were composed of reactants plus 494 solvent molecules for the water environment, 396 solvent molecules for the THF environment or 391 solvent molecules for the methanol environment. The boxes were periodic and tetragonal systems with $c / a=1.5$ where $a$ was about 25, 27, and $33 \AA$ for water, methanol, and THF,

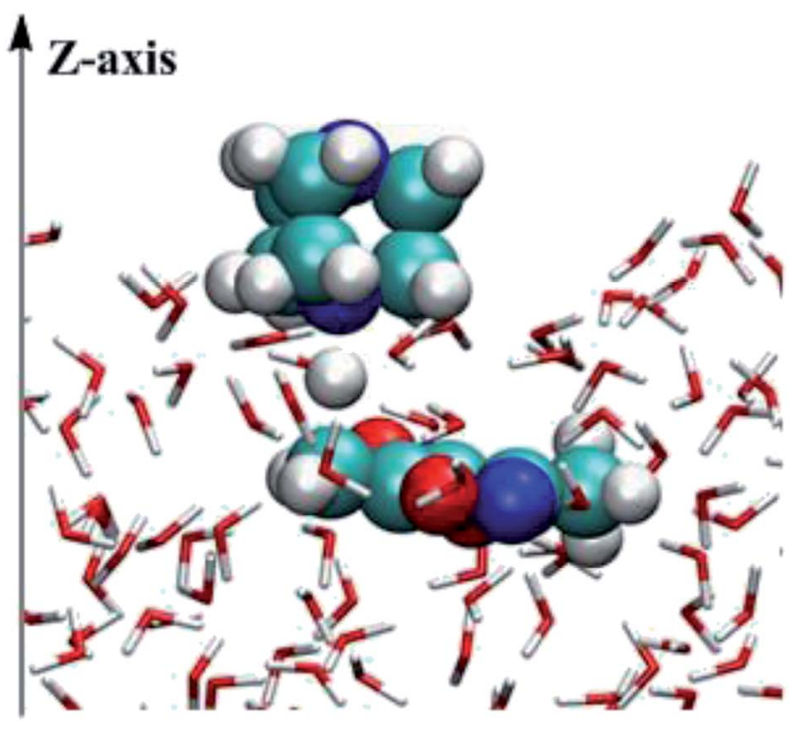

Fig. 1 Illustration of the on-water transition structure for the proton migration process of the DACBO-catalyzed vinylogous Henry reaction of isatin with 3,5-dimethyl-4-nitroisoxazole on-water from QM/MM calculations. 
respectively. FEP calculations were carried out in combination with NVT and NPT Metropolis MC simulations for on-water and in organic solvent environments.

As shown in Fig. 1, calculations for the reaction on-water were performed in a similar manner to those for the homogeneous solution-phase (in $\mathrm{CH}_{3} \mathrm{OH}$ and THF, Fig. S1 and S2 in ESI $\dagger$ ), expect that the periodicity was removed from the $z$ axis of a box with the explicit 494 water molecules and the two solutes, i.e., DABCO and 3,5-dimethyl-4-nitroisoxazole 2. In addition, the catalyst DABCO was on the top of the $z$ axis. Hence, an essential orientation analysis of multiple snapshots of reactants relative to the surface of the slab (perpendicular to the $z$ axis) found that the DABCO was inclined to lie almost flat on the surface of the water slab and reactant 2 was placed in the water. The structure demonstrates that the on-water reaction of DABCO and 2 takes place in the interface between the gas phase and the liquid phase.

One-dimensional free energy profiles were established by utilizing the distance of one transforming bond, RC1, as the reaction coordinate shown in Fig. 2. The reactant state was defined by $R_{8 \mathrm{C}-4 \mathrm{~N}}=3.50 \AA$ and $\mathrm{RC} 1=1.2 \AA$. The free energy profiles were flat in the vicinity of the reactant state. For the reacting system, each window of a FEP calculation entailed 60 million configurations of equilibration followed by 80 million configurations of averaging by using increments of $0.01 \AA$ for the RC1. Solute-solvent and solvent-solvent intermolecular cutoff distances of $12 \AA$ were employed for the reacting system on-water, in methanol, and in THF. The entire solute-solvent or solvent-solvent interaction was computed if any distance was within the cutoff. Adjustments to the allowed ranges for rotations, translations, and dihedral angle movements led to overall acceptance rates of $30-50 \%$ and solute move acceptance rates of $3-30 \%$ for new configurations. The ranges for bond stretching and angle bending were set automatically by the BOSS program on the basis of force constants and temperature. All QM/MM/ MC simulations were run on a Linux cluster.

All the optimized geometrical structures were obtained by performing the DFT calculations using the B3LYP ${ }^{46,47}$ method with the $6-31+\mathrm{G}(\mathrm{d}, \mathrm{p})$ basis set and the polarizable continuum solvation model $\mathrm{SMD}^{48}$ in the Gaussian 09 program. ${ }^{49}$ The harmonic frequency calculations at the same level were carried

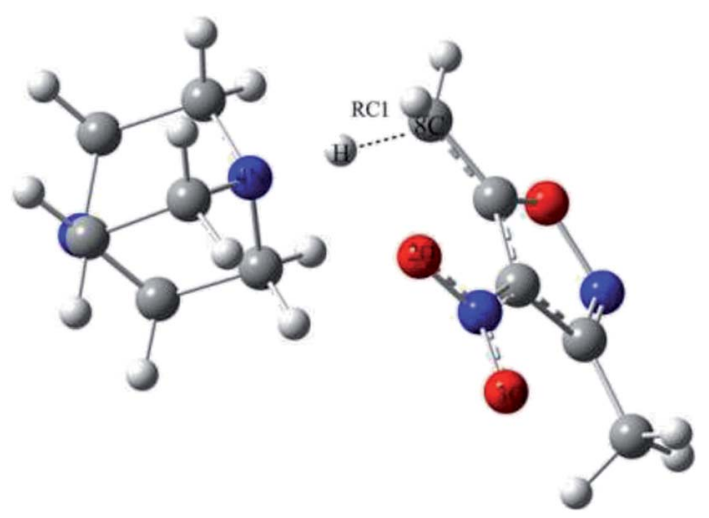

Fig. 2 Reaction coordinate RC1 for the proton transfer of the reaction. out to ensure that all stationary points were either as ground states with all-positive frequencies or transition structures (TSs) with only one imaginary frequency. The intrinsic reaction coordinate $(\text { IRC })^{50}$ calculations were conducted to check the energy profiles connecting each TS to the two associated minima. The Gibbs free energy corrections at $298.15 \mathrm{~K}$ and $101.325 \mathrm{kPa}$ were obtained from frequency calculations. The solvent effects in the three solvents were taken into account with the B3LYP/SMD/6-31+G(d,p) level. Moreover, the singlepoint energy calculations were also performed at the M06-2X/ SMD/6-311+G(d,p) levels by using the B3LYP/SMD/6-31+G(d,p) optimized structures. All the optimization structures of the reactants, transition states, intermediates, and products are shown in the ESI. $\dagger$

\section{Results and discussion}

We investigated the three feasible reaction pathways for the vinylogous Henry reaction of isatin 1a with 3,5-dialkyl-4nitroisoxazole 2 in water for exploring the functions of water and the catalyst DABCO. Subsequently, we considered the solvent effects in three solvents: water, THF and methanol. Then, microsolvent models were employed for the rate-limiting step. Finally, QM/MM/MC simulations were carried out for the rate-determining step and the roles of the solvents were analyzed in detail.

\subsection{Reaction mechanism in water studied by DFT calculations}

For this vinylogous Henry reaction, we proposed three reasonable pathways: Paths A-C, as shown in Scheme 2. In Path A, DABCO directly catalyzes the reaction of $\mathbf{1 a}$ with 2 . The reaction begins with hydrogen transfer, where the hydrogen atom at the $8 \mathrm{C}$ atom of the $\mathrm{CH}_{3}$ group in reactant 2 transfers to the $4 \mathrm{~N}$ atom of DABCO, followed by formation of a new $\mathrm{C}-\mathrm{C}$ bond between $\mathrm{C}$ of $1 \mathrm{a}$ and $8 \mathrm{C}$ of 2 . The last step is the transferring of the hydrogen atom of $4 \mathrm{~N}$ in DABCO to the $5 \mathrm{O}$ atom of $1 \mathrm{a}$ and hydroxyl formation. In Path $\mathrm{B}$, it initiates when one water molecule is activated by DABCO through transferring its one $\mathrm{H}$ atom to the $\mathrm{N}$ atom of $\mathrm{DABCO}$ and then accepting the proton from $-\mathrm{CH}_{3}$ in 2 . The following step is the $\mathrm{C}-\mathrm{C}$ bond formation, which is the same as Path A. The last step is hydroxyl forming by means of an auxiliary water molecule. For Path C, three auxiliary water molecules are involved in the deprotonation of $-\mathrm{CH}_{3}$ in 2 without the catalyst DABCO. There are two steps in the reaction. In the first step, the hydrogen atom at $8 \mathrm{C}$ of 2 transfers to one water molecule of a three-water-molecule chain. The second step is the simultaneous formation of a $\mathrm{C}-\mathrm{C}$ bond and a hydrogen atom combining with the $5 \mathrm{O}$ atom to form hydroxyl.

The free energy profiles of the three pathways mentioned above are depicted in Fig. S3 in the ESI. $\uparrow$ The results of the free energy barriers of activation for each elementary step obtained using the B3LYP/SMD/6-31+G(d,p) and M06-2X/SMD/6$311++\mathrm{G}(\mathrm{d}, \mathrm{p}) / / \mathrm{B} 3 \mathrm{LYP} / \mathrm{SMD} / 6-31+\mathrm{G}(\mathrm{d}, \mathrm{p})$ methods are listed in Table 1 . The two levels give similar results and the same trend. The following discussion is performed based on the DFT 


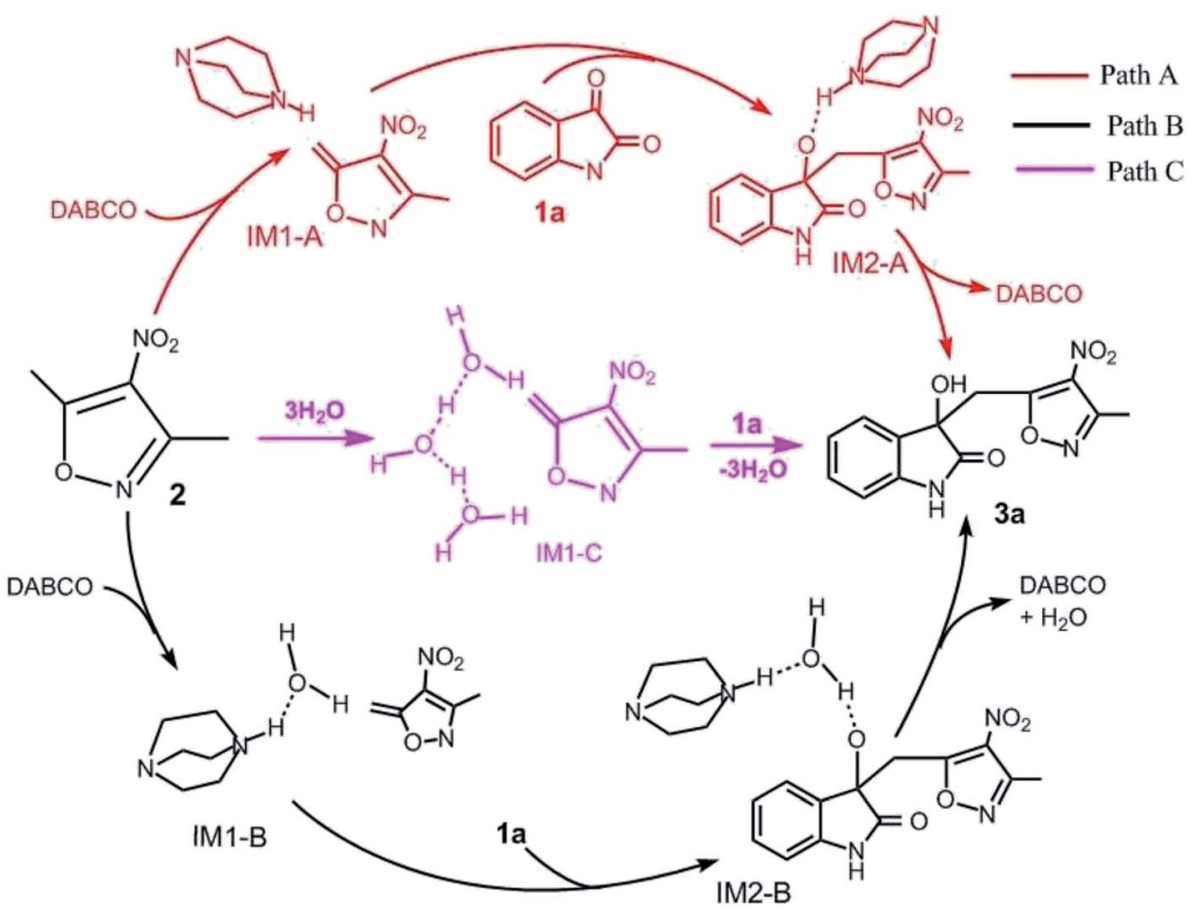

Scheme 2 Three possible reaction pathways of vinylogous Henry reactions between 3,5-dialkyl-4-nitroisoxazole and isatin in water.

methods M06-2X/SMD/6-311++G (d,p)//B3LYP/SMD/6$31+\mathrm{G}(\mathrm{d}, \mathrm{p})$ used. As one can see from Table 1 , it is relatively difficult for Path $\mathrm{C}$ to take place with the high free energy barriers of $34.0 \mathrm{kcal} \mathrm{mol}^{-1}$ for step 1 and $6.1 \mathrm{kcal} \mathrm{mol}^{-1}$ for step 2 compared with the other two pathways. For Path B, the free energy of activation of step 1 is $27.6 \mathrm{kcal} \mathrm{mol}^{-1}$. The subsequent two steps are easy to occur with low or even no free energy barriers. Path A is also a three-step process with free energies of activation of $21.2,5.0$, and $-2.4 \mathrm{kcal} \mathrm{mol}^{-1}$, respectively. Meanwhile, the rate-determining step of all Paths A, B, and C is the first step (the deprotonation of the $-\mathrm{CH}_{3}$ group in 2). Obviously, by comparison, the most preponderant route is Path A with the lowest free energy barrier of $21.2 \mathrm{kcal} \mathrm{mol}^{-1}$ in its rate-determining step. Thus, the presence of catalyst DABCO significantly reduces the free energy barrier.

Table 1 Free energy of activation, $\Delta G^{\neq}\left(\mathrm{kcal} \mathrm{mol}^{-1}\right)$, calculated at $25^{\circ} \mathrm{C}$ and $1 \mathrm{~atm}$, for three mechanisms of vinylogous Henry reactions between 3,5-dialkyl-4-nitroisoxazole and isatin in water

\begin{tabular}{llcc}
\hline \multirow{2}{*}{ Pathway } & Step & $\begin{array}{c}\text { B3LYP/SMD/ } \\
6-31+\mathrm{G}(\mathrm{d}, \mathrm{p})\end{array}$ & $\begin{array}{l}\text { M06-2X/SMD/6-311++G(d,p)/ } \\
\text { /B3LYP/SMD/6-31+G(d,p) }\end{array}$ \\
\hline \multirow{2}{*}{ Path A } & 1 & 22.4 & 21.2 \\
& 2 & 7.6 & 5.0 \\
\multirow{3}{*}{ Path B } & 3 & -1.0 & -2.4 \\
& 1 & 26.9 & 27.6 \\
& 2 & 7.0 & 4.9 \\
Path C & 3 & -0.2 & -0.6 \\
& 1 & 35.0 & 34.0 \\
& 2 & 7.6 & 6.1
\end{tabular}

\subsection{Effects of solvents studied by DFT calculations with the SMD model}

Next, we focus on the solvent effects on the dynamic property in the rate-determining step (the first step, the deprotonation of the $-\mathrm{CH}_{3}$ group in 2) of the favored Path A under different solvents containing water, methanol, and THF. The free energy values of the related reactants and transition states in THF and methanol were also calculated at the M06-2X/SMD/6$311++\mathrm{G}(\mathrm{d}, \mathrm{p}) / / \mathrm{B} 3 \mathrm{LYP} / \mathrm{SMD} / 6-31+\mathrm{G}(\mathrm{d}, \mathrm{p})$ level, which was the same as used in water. The final free energies of activation in water, $\mathrm{CH}_{3} \mathrm{OH}$, and THF obtained using the B3LYP/SMD/6$31+\mathrm{G}(\mathrm{d}, \mathrm{p})$ and M06-2X/SMD/6-311+G(d,p)//B3LYP/SMD/6$31+\mathrm{G}(\mathrm{d}, \mathrm{p})$ methods are listed in Table 2 . One can see from Table 2 that the free energy barriers of activation $\Delta G^{\neq}$are 22.4, 20.3, and $21.7 \mathrm{kcal} \mathrm{mol}^{-1}$ using B3LYP/SMD/6-31+G(d,p) as well as 21.2, 19.4, and $21.2 \mathrm{kcal} \mathrm{mol}^{-1}$ using M06-2X/SMD/6$311++\mathrm{G}(\mathrm{d}, \mathrm{p}) / / \mathrm{B} 3 \mathrm{LYP} / \mathrm{SMD} / 6-31+\mathrm{G}(\mathrm{d}, \mathrm{p})$ in water, $\mathrm{CH}_{3} \mathrm{OH}$, and

Table 2 Free energies of activation, $\Delta G^{\neq}\left(\mathrm{kcal} \mathrm{mol}^{-1}\right)$, calculated at $25^{\circ} \mathrm{C}$ and $1 \mathrm{~atm}$ for the rate-determining step of vinylogous Henry reactions between 3,5-dialkyl-4-nitroisoxazole and isatin in different solvents

\begin{tabular}{llll}
\hline Solvent & & $\begin{array}{l}\text { B3LYP/SMD/ } \\
6-31+\mathrm{G}(\mathrm{d}, \mathrm{p})\end{array}$ & $\begin{array}{l}\text { M06-2X/SMD/6-311++G(d,p)/ } \\
/ \text { B3LYP/6-31+G(d,p) }\end{array}$ \\
\hline \multirow{2}{*}{ Water } & $0-\mathrm{H}_{2} \mathrm{O}$ & 22.4 & 21.2 \\
& $1-\mathrm{H}_{2} \mathrm{O}$ & 22.4 & 21.0 \\
& $3-\mathrm{H}_{2} \mathrm{O}$ & 22.1 & 21.2 \\
& $6-\mathrm{H}_{2} \mathrm{O}$ & 22.0 & 20.6 \\
$\mathrm{CH}_{3} \mathrm{OH}$ & & 20.3 & 19.4 \\
$\mathrm{THF}^{*}$ & & 21.7 & 21.2
\end{tabular}


THF, respectively. All the computed $\Delta G^{\neq}$values in organic solvents are lower than those in water, indicating that the DACBO-catalyzed vinylogous Henry reaction takes place more easily in organic solvents than in water. However, the results are inconsistent with the experimental research, in which the reaction rate in water is faster than those in THF and methanol. ${ }^{29}$

Whereafter, for the rate-determining step of Path A in water, microsolvent models with the introduction of one-, three-, and up to six-water clusters to the reaction centers were employed to simulate the local microhydration surrounding (the corresponding geometry structures of the reactants, transition states, and intermediates are given in Fig. S4 of the ESI $\dagger$ ). The free energy of activation values $\Delta G^{\neq}$are also given in Table 2. It can be seen that the $\Delta G^{\neq}$values for the microsolvent models are slightly decreased compared with the one in water without the assistance of the water cluster and still higher than those in THF and methanol. This indicates that the calculations using the implicit SMD solvent model without or with the involvement of auxiliary water molecules are unfit to reproduce the experimentally observed changes of the rate of this vinylogous Henry reaction in water and organic solvents. It is noteworthy that some investigations using the DFT methods and the polarizable continuum solvation models also failed to represent the accurate sequence of reaction rates for the 1,3-dipolar cycloadditions, ${ }^{35,36}$ the allyl $p$-tolyl ether rearrangement, ${ }^{37}$ and the uncatalyzed aldol reaction ${ }^{38}$ in solution. Thus, it should be realized that the specific changes of hydrogen bond interactions between reaction molecules and solvents along the reaction path are important to the reaction under an "on-water" environment, but they are not reflected in the continuum treatment. Therefore, the QM/MM/MC calculations for the rate-limiting step of Path A in the title reaction were performed (under the solution conditions: on-water, in $\mathrm{CH}_{3} \mathrm{OH}$, and in THF, for comparison) to gain an explicit representation of solvent molecules in the following work.

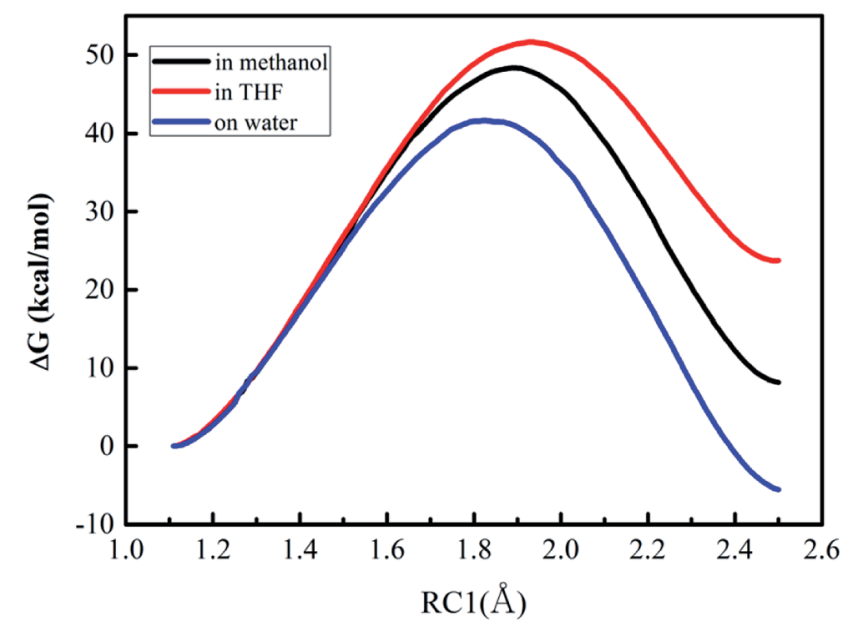

Fig. 3 Free energy profiles for the proton transfer (the first step of Path A) in three different solvents.
Table 3 Calculated bond lengths $(\AA)$ of reaction coordinate RC1 in transition state for the proton transfer of DACBO-catalyzed vinylogous Henry reaction between isatin and 3,5-dimethyl-4-nitroisoxazole from two methods

\begin{tabular}{lll}
\hline System & B3LYP/SMD/6-31+G(d,p) & QM/MM/MC/PDDG/PM3 \\
\hline On-water & 1.36 & 1.83 \\
In $\mathrm{CH}_{3} \mathrm{OH}$ & 1.37 & 1.89 \\
In THF & 1.44 & 1.93 \\
\hline
\end{tabular}

\subsection{Role of solvents in the rate-limiting step studied by QM/ MM MC simulations}

3.3.1 Structures. Geometries for the proton transfer in the first step of the DACBO-catalyzed vinylogous Henry reaction between $1 \mathrm{a}$ and 2 in solution were located with the QM/MM/MC simulations. Configurationally averaged free energy profiles, $\Delta G$ ( $\mathrm{kcal} \mathrm{mol}^{-1}$ ), were calculated by perturbing the distance of the broken bond $8 \mathrm{C}-3 \mathrm{H}$ via potential of mean force (PMF) calculations in increments of $0.01 \AA$. All internal degrees of freedom, except for reaction coordinate RC1, were fully sampled during the simulations. The free energy profiles for the reactions onwater, in THF and in methanol are shown in Fig. 3. The initial ranges were from 1.12 to $2.50 \AA$ for RC1. From the free energy profiles, the rate-determining step in the three different solvents was a one-step reaction with only one transition structure. The feasibility of false data was eliminated firstly, then we concluded all potential factors and inferred that the deviation between reaction rates may be attributed to the solvent effect, which plays a large role in organic reactions.

The values of RC1 in the transition state of the proton migration process in the three solvent conditions were computed from DFT method and QM/MM/MC simulations, respectively, and are listed in Table 3 . It is explicit that the geometrical structures of the transition states in the three different solvents did not have large variations with RC1 lengths of $1.89 \pm 0.05 \AA$ from the QM/MM/MC/PDDG/PM3 method and $1.37 \pm 0.07 \AA$ from the B3LYP/SMD/6-31+G(d,p) method. It can be also seen that the change tendency of RC1 length along the solvent polarity computed by the QM/MM/MC simulations with PDDG/PM3 as the QM method was similar to the one by using DFT at the B3LYP/SMD/6-31+G(d,p) level of theory although the absolute values of RC1 distance at the TSs from the former simulation were much longer than those obtained from the latter method. The $\mathrm{QM} / \mathrm{MM} / \mathrm{MC}$ simulations predicted the transition states to be more product-like.

Table 4 Free energy changes relative to reactants, $\Delta G\left(\mathrm{kcal} \mathrm{mol}^{-1}\right)$, calculated at $25^{\circ} \mathrm{C}$ and $1 \mathrm{~atm}$, for the proton migration process (the first step of Path A) of DACBO-catalyzed vinylogous Henry reaction of isatin with 3,5-dimethyl-4-nitroisoxazole obtained from the QM/MM/ MC simulations with PDDG/PM3 as the QM method

\begin{tabular}{lccc}
\hline System & On-water & In $\mathrm{CH}_{3} \mathrm{OH}$ & In THF \\
\hline Reactant & 0.0 & 0.0 & 0.0 \\
TS & 41.6 & 48.4 & 51.7 \\
Product & -5.6 & 8.1 & 23.7
\end{tabular}



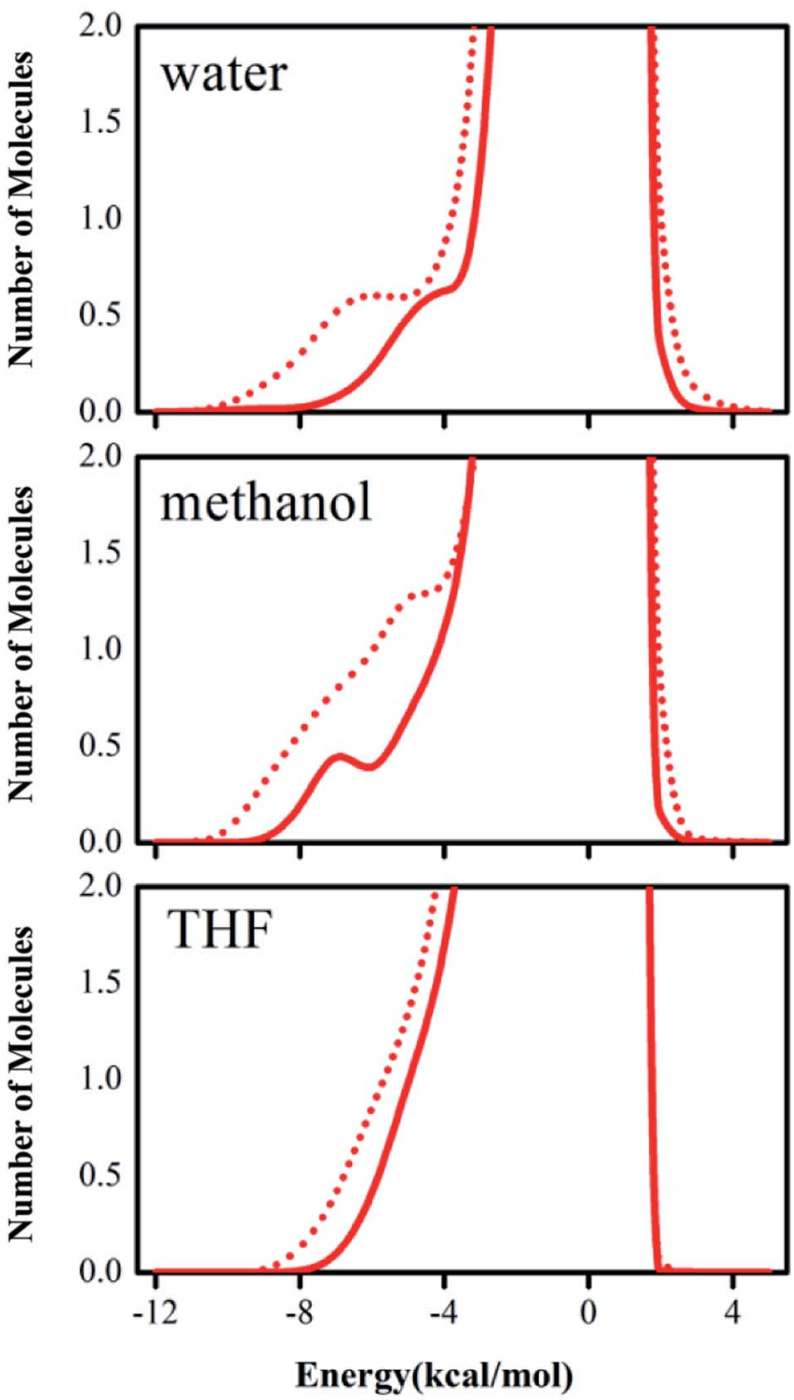

Fig. 4 Solute-solvent energy pair distributions for the proton transfer of the DACBO-catalyzed vinylogous Henry reaction for structures near the reactants (solid red) and transition states (dash red). The ordinate records the number of solvent molecules that interact with the solutes and their interaction energy is on the abscissa. Units for the ordinate are number of molecules per kcal per mol.

3.3.2 Energetics. The free energies in the three solvents at $25^{\circ} \mathrm{C}$ and $1 \mathrm{~atm}$ were calculated for the rate-determining step (the first step) of Path A of the DACBO-catalyzed vinylogous Henry reaction of isatin with 3,5-dimethyl-4-nitroisoxazole from the $\mathrm{QM} / \mathrm{MM} / \mathrm{MC}$ simulations beginning from a $3.5 \AA$ A separation distance between $\mathrm{DABCO}$ and 2 . The resultant free energy changes relative to the reactants are summarized in Table 4 and Fig. 3. The error ranges in the computed free energy values have been evaluated from fluctuations in the $\Delta G$ values for each FEP window by using the batch means procedure with batch sizes of 0.5 million configurations; the overall uncertainties in the computed free energies $\Delta G$ were below $0.7 \mathrm{kcal} \mathrm{mol}^{-1}$. From Tables 4 and 2, all the absolute $\Delta G^{\neq}$values from the QM/MM/ MC simulations are higher than the corresponding ones from DFT/SMD computation by about $20-30 \mathrm{kcal} \mathrm{mol}^{-1}$. It is
Table 5 Solute-solvent energy pair distributions for the proton transfer of the DACBO-catalyzed vinylogous Henry reaction for the reactants (GS) and transition structure (TS) under three solvent conditions integrated to $-4 \mathrm{kcal} \mathrm{mol}^{-1}$ from the results in Fig. 4

\begin{tabular}{llll}
\hline & On-water & In $\mathrm{CH}_{3} \mathrm{OH}$ & In THF \\
\hline GS & 2.6 & 2.6 & 2.9 \\
TS & 5.4 & 5.2 & 4.7 \\
$\Delta$ (TS-GS) & 2.8 & 2.6 & 1.8 \\
\hline
\end{tabular}

important to realize that the overestimation of the absolute $\Delta G^{\neq}$in the semiempirical PDDG/PM3 method is a systematic error and is not limited to this vinylogous Henry reaction. Similar discoveries have been reported for Diels-Alder reactions, ${ }^{51}$ ene reactions, ${ }^{52}$ methyl-transfer reactions, ${ }^{53}$ Claisen rearrangements, ${ }^{37}$ 1,3-dipolar cycloadditions, ${ }^{35}$ and aldol reactions. ${ }^{38}$

As described in Fig. 3, the free energy profiles reveal that the proton transfer process for the DACBO-catalyzed vinylogous Henry reaction undergoes a one-step mechanism under the three different solvent conditions. From Table 4, the free energies of activation from QM/MM/MC simulations were 41.6, 48.4 , and $51.7 \mathrm{kcal} \mathrm{mol}^{-1}$ for on-water, in methanol and in THF, respectively. We found that the $\Delta G^{\neq}$value on the surface of water is approximately $7-10 \mathrm{kcal} \mathrm{mol}^{-1}$ lower than those in methanol and in THF and the $\Delta G$ values of the product are also much lower. Therefore, it could be concluded that the ratedetermining step of Path A of the DACBO-catalyzed vinylogous Henry reaction on-water takes place more easily than in methanol and in THF and that the rate change in three different solvent conditions follows the order of "on-water" > "in methanol" > "in THF", which is in great accordance with the experiment research. ${ }^{29}$

3.3.3 Solute-solvent energy pair distributions. As is well known, water, as a polar molecule, is a great hydrogen bond acceptor and donor. ${ }^{54}$ In previous theoretical studies of the Henry reaction, ${ }^{55,56}$ the solvent effect was a remarkable factor for the reaction rate through hydrogen bonding stabilizing the transition structures. For the DACBO-catalyzed vinylogous Henry reaction here, there are strong hydrogen-bonding reception sites at $2 \mathrm{O}$ and $3 \mathrm{O}$ atoms in reactant 2 . Additionally, water can form more and stronger hydrogen bond than methanol and THF because water is a strongly polar solvent. The present results are fully consistent with these ideas. Subsequently, the detailed insights into the changes in the hydrogenbonding interactions in different solvents along the ratelimiting step are discussed below.

The computed tendency of the rate change reflected by the free energy of activation for the title reaction, as mentioned above, which is in agreement with the experimental results, indicates that the QM/MM/MC calculations obtained the origin of the solvent effect at the molecular level. In particular, the hydrogen bond interactions between the reaction system and solvent molecules can be described by the solute-solvent energy pair distributions that record average number of solvent molecules interacting with the solute and the associated interaction 
energy. Through analyzing the $\mathrm{QM} / \mathrm{MM} / \mathrm{MC}$ results near the reactant state and at the transition structure FEP windows, the interaction energies were obtained. The solute-solvent energy pair distributions for the proton transfer process between reactant 2 and DABCO on-water, in methanol, and in THF are shown in Fig. 4. The hydrogen bonds on-water and in methanol are found in the left-most region with solute-solvent interaction energies more attractive than $-4 \mathrm{kcal} \mathrm{mol}^{-1}$. The most favorable dipole-dipole electrostatic interactions in THF cover the region from -10 to $-5 \mathrm{kcal} \mathrm{mol}^{-1}$. The large bands near $0 \mathrm{kcal} \mathrm{mol}{ }^{-1}$ result from the weak interactions with the outer shells of many distant solvent molecules.

According to Fig. 4, with comparison of bands in solid red lines and dashed red lines, we can see that the transition structures have a stronger band than those of the reactant structures for on-water, in methanol, and in THF, respectively. Furthermore, there are remarkable differences between onwater and in non-aqueous solvent. The low-energy bands for the aprotic solvent are less favorable interactions than those for on-water. In "on-water", strong solute-solvent interactions were obvious for the reactants and transition structure, with the interaction energies in the range from -10 to $-4 \mathrm{kcal} \mathrm{mol}^{-1}$. The results of the solute-solvent energy pair distributions under three solvent conditions integrated to $-4 \mathrm{kcal} \mathrm{mol}^{-1}$ are listed in Table 5.

In Table 5, it is clear that the variations of solute-solvent interactions for proton transfer from reactants to the TSs have the same tendency under the three different solvent environments. Integration of the transition structure band from -12 to

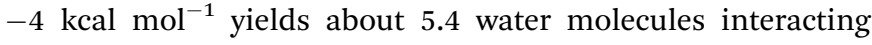
strongly with the solute for the on-water condition, 5.2 methanol molecules in methanol, and 4.7 tetrahydrofuran molecules in THF. Therefore, the interaction intensity of the reaction system with solvent molecules is changed in the order of tetrahydrofuran < methanol < water. In all solvent conditions, the number of hydrogen bonds between solvent and solute for the TS is greater than that for the reactants, indicating that the reduction in the free energy of activation can be attributed to the heightened hydrogen bond interactions in the transition structure. Furthermore, the numbers of solvent molecules strongly interacting with the solute increase by $2.8,2.6$, and 1.8 "on-water", in $\mathrm{CH}_{3} \mathrm{OH}$, and in THF, respectively, on going from reactants to transition state. These results show that the stabilization of the transition structure relative to its reactant is different in different solvents. In "on-water" and methanol, the better solvation of the TS is owing to the larger increase in the extent of the solute-solvent hydrogen bond interaction, while in THF the change for the interactions with the solvent along the reaction path is smaller.

3.3.4 Radial distribution functions (rdfs). The radial distribution function (rdf), $g(R)$, can be used to further characterize the solute-solvent structures for the first step (proton transfer) of the DACBO-catalyzed vinylogous Henry reaction onwater, in methanol and in THF. The $g(R)$ value is calculated by the following equation:

$$
g_{\mathrm{xy}}(R)=\mathrm{d} N /\left(4 \pi \rho R^{2} \mathrm{~d} R\right)=<N(R, R+\mathrm{d} R)>/\left(4 \pi \rho R^{2} \mathrm{~d} R\right)
$$

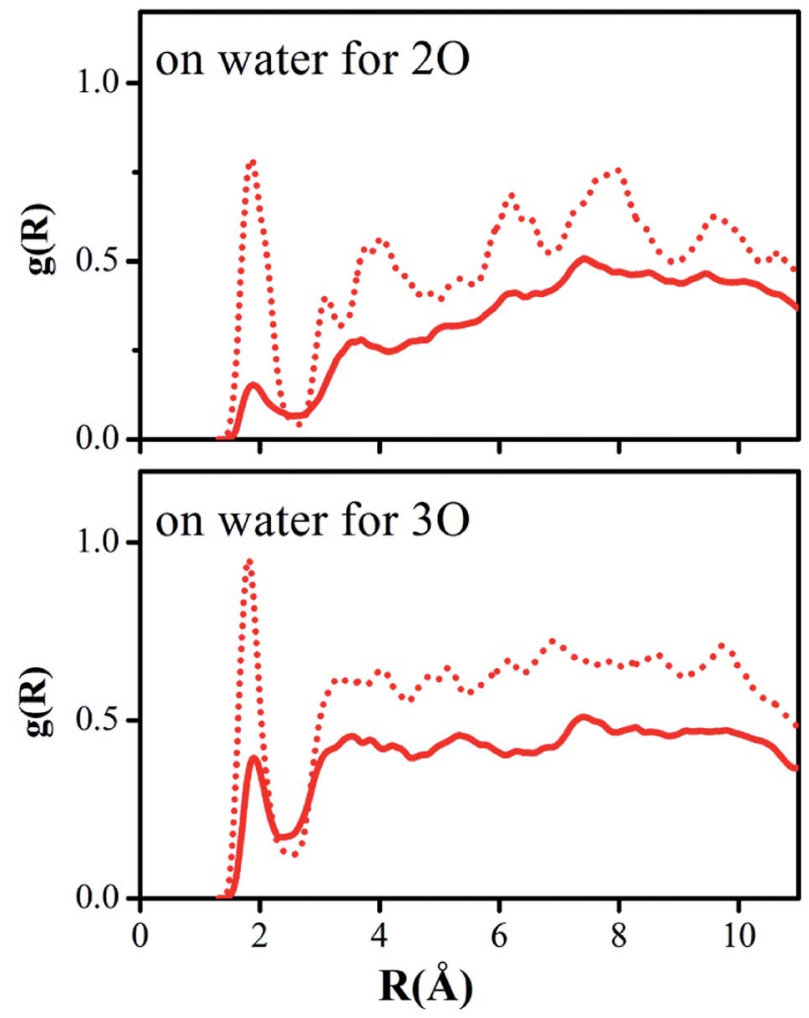

Fig. 5 Computed $\mathrm{O}$ (solute) $-\mathrm{H}$ (water) radial distribution functions for the rate-limiting step of DACBO-catalyzed vinylogous Henry reaction on-water: transition structure (dash red), reactant (solid red) at $25^{\circ} \mathrm{C}$ and $1 \mathrm{~atm}$.

The $g_{\text {xy }}(R)$ value gives the probability of the occurrence of an atom of type y at a distance $R$ from an atom of type x, normalized to account for the bulk density $\rho$ of the atoms and for the volume element $4 \pi R^{2} \mathrm{~d} R$.

Hydrogen bonding between the oxygen atoms $2 \mathrm{O}$ and $3 \mathrm{O}$ in the $\mathrm{NO}_{2}$ group of reactant 2 and the hydrogen atoms of water or methanol, $\mathrm{O}$ (solute)-H(solvent), should yield contacts shorter than $2.7 \AA$ A. Fig. 5 and 6 depict the computed $g(R)$ values of the $\mathrm{O}$ (solute) $-\mathrm{H}($ solvent) radial distribution functions for the reactant and transition structures in the rate-limiting step of the DACBO-catalyzed vinylogous Henry reaction "on-water" and in $\mathrm{CH}_{3} \mathrm{OH}$, which reflect the probability of finding the hydrogen atom of the solvent molecules at a distance $R$ from the oxygen atom of the reaction system.

As illustrated in Fig. 5 and 6, both for $2 \mathrm{O}$ and $3 \mathrm{O}$, we can see that the hydrogen bonds are obviously greater for the transition state (TS) compared to those of the reactant structures, with a well-defined first peak centered at $1.9 \AA$ and a minimum near 2.4-2.7 $\AA$. The second peak in the $\mathrm{O}$ (solute)-H(solvent) rdf at 3.2-3.8 $\AA$ is owing to the more remote hydrogen of the linearly hydrogen-bonding solvent molecules. However, from the $2 \mathrm{O}$ atom, the integration of peaks from 0.0 to the minima at 2.4-2.7 $\AA$ reveals an increased number of site-specific $2 \mathrm{O}$ (solute)$\mathrm{H}$ (solvent) hydrogen bonds for the TS relative to the reactants on-water and in methanol, namely, from GS to TS it is 0.2 to 0.7 for on-water and 0.1 to 0.5 for in methanol (Table 6). 

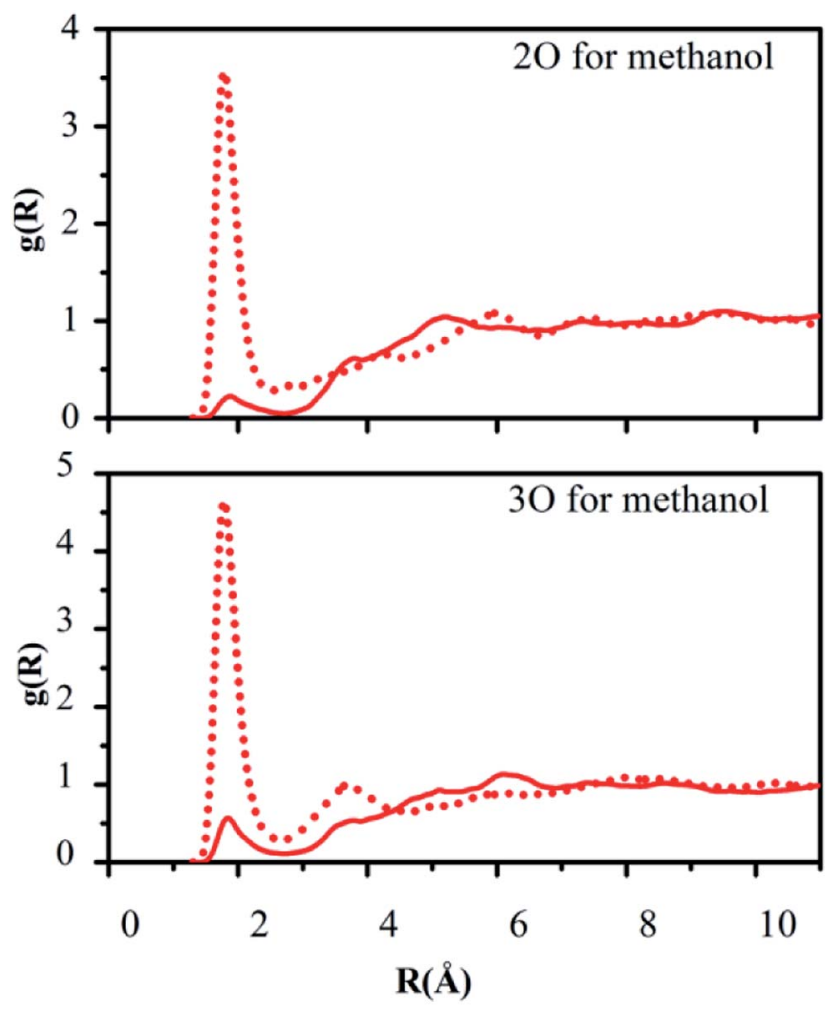

Fig. 6 Computed $\mathrm{O}$ (solute) $-\mathrm{H}$ (methanol) radial distribution functions for the rate-limiting step of DACBO-catalyzed vinylogous Henry reaction in methanol: transition structure (dash red), reactant (solid red) at $25^{\circ} \mathrm{C}$ and $1 \mathrm{~atm}$.

Analogously, there are hydrogen bonds for 30 in the TS, reaching 1.0 for on-water and 0.7 for in methanol. It changes from 0.6 to 1.7 for on-water, and from 0.3 to 1.2 for in methanol. The increase of hydrogen bond interactions between the $\mathrm{O}$ (solute) and $\mathrm{H}$ (solvent) from the reactants to TS for on-water is more than that in methanol. This could be the major reason leading to the greater reaction acceleration on-water than in $\mathrm{CH}_{3} \mathrm{OH}$.

As depicted in Fig. S5 of the ESI, $\dagger$ the interactions between the oxygen of the reactant and the united-atom $\mathrm{CH}_{2}$ group on THF, O(solute) $\cdots \mathrm{CH}_{2}$ (solvent), were also detected by radial distribution functions for the reactant and transition state. We found that the probability of finding the $\mathrm{CH}_{2}$ group on THF

Table 6 Number of solvent molecules interacting with oxygen atoms of solute for reactant (GS) and transition state (TS) in the proton transfer process on-water and in methanol from radial distribution functions $^{a}$

\begin{tabular}{llllll}
\hline & On-water & & & \multicolumn{2}{l}{ In methanol } \\
\cline { 2 - 3 } & GS & TS & & GS & TS \\
\hline 20 & 0.2 & 0.7 & 0.1 & 0.5 \\
30 & 0.4 & 1.0 & & 0.2 & 0.7 \\
Total & 0.6 & 1.7 & 0.3 & 1.2
\end{tabular}

${ }^{a}$ Integration of the first peak to $2.4-2.7 \AA$ from the results shown in Fig. 5 and 6. molecule from the oxygen atom of the solute requires a larger distance $R$ compared to those "on-water" or in methanol. The $\mathrm{O} \cdots \mathrm{CH}_{2}$ interactions are reflected in the first peak centered at around $3.6 \AA$, which is extended to its minimum with a distance of about $4.5 \AA$. The second peak in the $\mathrm{O} \cdots \mathrm{CH}_{2}$ rdf at around 5.5 $\AA$ arises from the more remote united-atom $-\mathrm{CH}_{2}$ group of the THF molecules. Consistent with the results in Fig. S5, $\dagger$ the difference between the reactant and transition state is much diminished in comparison to the results for on-water and in methanol.

\section{Conclusion}

In conclusion, three feasible pathways for the DACBO-catalyzed vinylogous Henry reaction between 3,5-dialkyl-4-nitroisoxazole and isatin have been explored theoretically under water as the solvent by DFT calculations: (A) direct catalyzation of DACBO; (B) attacking of one water molecule activated by the catalyst; and (C) catalyzation of three auxiliary water molecules without catalyst. We found that Path $\mathrm{A}$ is the most favorable mechanism and the first step, the proton migration process, is the ratelimiting step. Additionally, the solvent effects of three different solvents, namely, water, methanol, and tetrahydrofuran, have been considered by DFT methods with SMD model. The microsolvent models with one-, three-, or six-watermolecule clusters have also been adopted for the ratedetermining step in water. However, the results of solvent effects obtained from DFT calculations are contrary to the experimental research of Zhang et al. $^{29}$

QM/MM/MC simulations have been carried out for the ratelimiting step of Path A in the title reaction on the water surface, in methanol and in tetrahydrofuran. The calculated $\Delta G^{\neq}$values of $41.6,48.4$ and $51.7 \mathrm{kcal} \mathrm{mol}^{-1}$ under on-water, in methanol and in THF, respectively, indicate that the reaction rate order is "on-water" > "in methanol" > "in THF". This qualitatively agrees with the experimental observation. Furthermore, the hydrogenbonding effects are better in the reaction on-water than in the other two solvents. The reaction rate acceleration for the proton transfer step is connected with the on-water environment because of the ability of the interfacial water molecules to stabilize the transition structure. Solute-solvent energy pair distribution and radial distribution functions further expound the increase of site-specific (2O and 30 atoms in reactant 2) hydrogen bond interactions in the transition structure in the rate-determining step. Therefore, our studies will broaden the understanding of the reaction mechanism and the role of water for the vinylogous Henry reaction theoretically.

\section{Conflicts of interest}

There are no conflicts to declare.

\section{Acknowledgements}

This project has been supported by the National Natural Science Foundation of China (Grant No. 21573153). 


\section{References}

1 F. Q. Shi, X. Li, Y. Z. Xia, L. M. Zhang and Z.-X. Yu, J. Am. Chem. Soc., 2007, 129, 15503-15512.

2 S. Minakata and M. Komatsu, Chem. Rev., 2009, 109, 711724.

3 Y. Liang, H. L. Zhou and Z.-X. Yu, J. Am. Chem. Soc., 2009, 131, 17783-17785.

4 R. N. Butler and A. G. Coyne, Chem. Rev., 2010, 110, 63026337.

5 Y. Y. Zheng and J. P. Zhang, J. Phys. Chem. A, 2010, 114, 43254333.

6 M. B. Gawande, V. D. B. Bonifacio, R. Luque, P. S. Branco and R. S. Varma, Chem. Soc. Rev., 2013, 42, 5522-5551.

7 M. Sengoden and T. Punniyamurthy, Angew. Chem., Int. Ed., 2013, 125, 600-603.

8 H. Y. Yuan, Y. Y. Zheng, Z. X. Fang, X. H. Bi and J. P. Zhang, Green Chem., 2014, 16, 2653-2663.

9 J. B. F. N. Engberts and M. J. Blandamer, Chem. Commun., 2001, 1701-1708.

10 G. W. V. Cave, C. L. Raston and J. L. Scott, Chem. Commun., 2001, 2159-2169.

11 D. C. Riadeout and R. Breslow, J. Am. Chem. Soc., 1980, 102, 7816-7817.

12 S. Narayan, J. Muldoon, M. G. Finn, V. V. Fokin, H. C. Kolb and K. B. Sharpless, Angew. Chem., Int. Ed., 2005, 44, 32753279.

13 Y. Hayashi, Angew. Chem., Int. Ed., 2006, 45, 8103-8104.

14 J. E. Klijin and J. B. F. N. Engberts, Nature, 2005, 435, 746747.

15 C. J. Li, Chem. Rev., 2005, 105, 3095-3166.

16 C. J. Li and L. Chen, Chem. Soc. Rev., 2006, 35, 68-82.

17 A. Chanda and V. V. Fokin, Chem. Rev., 2009, 109, 725-748.

18 R. N. Butler and A. G. Coyne, Chem. Rev., 2010, 110, 63026337.

19 M. O. Simon and C. J. Li, Chem. Soc. Rev., 2012, 41, 14151427.

20 L. Henry and C. R. Hebd, C. R. Seances Acad. Sci. Roum., 1895, 120, 1265-1270.

21 A. Noole, K. Lippur, A. Metsala, M. Lopp and T. Kanger, J. Org. Chem., 2010, 75, 1313-1316.

22 Y. Zhang, Z. J. Li, H. S. Xu, Y. Zhang and W. Wang, RSC Adv., 2011, 1, 389-392.

23 M. Holmquist, G. Blay and J. R. Pedro, Chem. Commun., 2014, 50, 9309-9312.

24 G. Casiraghi, F. Zanardi, G. Appendino and G. Rassu, Chem. Rev., 2000, 100, 1929-1972.

25 G. Casiraghi, L. Battistini, C. Curti, G. Rassu and F. Zanardi, Chem. Rev., 2011, 111, 3076-3154.

26 C. Schneider and F. Abels, Org. Biomol. Chem., 2014, 12, 3531-3543.

27 A. R. Katritzky, C. W. Rees and E. F. V. Scriven, Comprehensive Heterocyclic Chemistry II, Oxford, 1996.

28 A. R. Katritzky, C. A. Ramsden, E. F. V. Scriven and R. J. K. Taylor, Comprehensive Heterocyclic Chemistry III, Oxford, 2008.
29 Y. Zhang, B. W. Wei, H. Lin, L. Zhang, J. X. Lin, H. Q. Luo and X. L. Fan, Green Chem., 2015, 17, 3266-3270.

30 Y. Zhang, B. W. Wei, L. N. Zou, M. L. Kang, H. Q. Luo and X. L. Fan, Tetrahedron, 2016, 72, 2472-2475.

31 G. Vayner, K. N. Houk, W. L. Jorgensen and J. I. Brauman, J. Am. Chem. Soc., 2004, 126, 9054-9058.

32 O. Acevedo and W. L. Jorgensen, Org. Lett., 2004, 6, 28812884.

33 O. Acevedo and W. L. Jorgensen, J. Am. Chem. Soc., 2005, 127, 8829-8834.

34 A. N. Alexandrova and W. L. Jorgensen, J. Phys. Chem. B, 2011, 115, 13624-13632.

35 X. Yang and Y. Xue, Phys. Chem. Chem. Phys., 2013, 15, 11846-11855.

36 X. Yang and Y. Xue, J. Org. Chem., 2014, 79, 4863-4870.

37 O. Acevedo and K. Armacost, J. Am. Chem. Soc., 2010, 132, 1966-1975.

38 J. M. Zhao, F. He, F. Zhang, X. Yang, Z. Y. Tian and Y. Xue, ChemPhysChem, 2017, 18, 2123-2131.

39 W. L. Jorgensen and J. Tirado-Rives, J. Comput. Chem., 2005, 26, 1689-1700.

40 M. P. Repasku, J. Chandrasekhar and W. L. Jorgensen, J. Comput. Chem., 2002, 23, 1601-1622.

41 I. Tuber-Brohman, C. R. W. Guimarăes, M. P. Repasky and W. L. Jorgensen, J. Comput. Chem., 2003, 25, 138-150.

42 J. D. Thompson, C. J. Cramer and D. G. Truhlar, J. Comput. Chem., 2003, 24, 1291-1304.

43 G. A. Kaminski, R. A. Friesner, J. Tirado-Rives and W. L. Jorgensen, J. Phys. Chem. B, 2001, 105, 6474-6487.

44 W. L. Jorgensen, D. S. Maxwell and J. Tirado-Rives, J. Am. Chem. Soc., 1996, 118, 11225-11236.

45 W. L. Jorgensen, J. Chandrasekhar, J. D. Madura, W. Impey and M. L. Klein, J. Chem. Phys., 1983, 79, 926-935.

46 A. D. Becke, J. Chem. Phys., 1993, 98, 5648-5652.

47 C. Lee, W. Yang and R. G. Parr, Phys. Rev., 1988, 37, 785-789. 48 A. V. Marenich, C. J. Cramer and D. G. Truhlar, J. Phys. Chem. $B$, 2009, 113, 6378-6396.

49 M. J. Frisch, G. W. Trucks, H. B. Schlegel, G. E. Scuseria, M. A. Robb, J. R. Cheeseman, G. Scalmani, V. Barone, B. Mennucci, G. A. Petersson, H. Nakatsuji, M. Caricato, X. Li, H. P. Hratchian, A. F. Izmaylov, J. Bloino, G. Zheng, J. L. Sonnenberg, M. Hada, M. Ehara, K. Toyota, R. Fukuda, J. Hasegawa, M. Ishida, T. Nakajima, Y. Honda, O. Kitao, H. Nakai, T. Vreven, J. A. Montgomery Jr, J. E. Peralta, F. Ogliaro, M. Bearpark, J. J. Heyd, E. Brothers, K. N. Kudin, V. N. Staroverov, T. Keith, R. Kobayashi, J. Normand, K. Raghavachari, A. Rendell, J. C. Burant, S. S. Iyengar, J. Tomasi, M. Cossi, N. Rega, J. M. Millam, M. Klene, J. E. Knox, J. B. Cross, V. Bakken, C. Adamo, J. Jaramillo, R. Gomperts, R. E. Stratmann, O. Yazyev, A. J. Austin, R. Cammi, C. Pomelli, J. W. Ochterski, R. L. Martin, K. Morokuma, V. G. Zakrzewski, G. A. Voth, P. Salvador, J. J. Dannenberg, S. Dapprich, A. D. Daniels, O. Farkas, J. B. Foresman, J. V. Ortiz, J. Cioslowski and D. J. Fox, Gaussian 09, Revision D.01, Gaussian, Wallingford CT, 2010. 
50 C. Gonzalez and H. B. Schlegel, J. Phys. Chem., 1990, 94, 5523-5527.

51 O. Acevedo and W. L. Jorgensen, J. Chem. Theory Comput., 2007, 3, 1412-1419.

52 A. N. Sheppard and O. Acevedo, J. Am. Chem. Soc., 2009, 131, 56 D. Zorn, V. S.-Y. Lin, M. Pruski and M. S. Gordon, J. Phys. 2530-2540.

53 H. Gunaydin, O. Acevedo, W. L. Jorgensen and K. N. Houk, J. Chem. Theory Comput., 2007, 3, 1028-1035.
54 V. Polo, L. R. Domingo and J. Andrés, J. Phys. Chem. A, 2005, 109, 10438-10444.

55 J. Kostal, A. M. Voutchkova and W. L. Jorgensen, Org. Lett., 2012, 14, 260-263. Chem. A, 2008, 112, 10635-10649. 